Research Article

\title{
Measuring the Impact of an AI-Enabled Mobile Application for University Students
}

\author{
Sayed S. Younes $\mathbb{D}^{D}$, Abdulmohsin H. Alharbi $\mathbb{D}^{\circ}$, and Mahmoud M. Aboeldahab \\ Umm Al-Qura University, Makkah 21955, Saudi Arabia \\ Correspondence should be addressed to Sayed S. Younes; ssyounes@uqu.edu.sa
}

Received 1 July 2021; Revised 23 July 2021; Accepted 30 July 2021; Published 6 August 2021

Academic Editor: Fazlullah Khan

Copyright (c) 2021 Sayed S. Younes et al. This is an open access article distributed under the Creative Commons Attribution License, which permits unrestricted use, distribution, and reproduction in any medium, provided the original work is properly cited.

\begin{abstract}
This study developed an artificial intelligence- (AI-) enabled mobile application for smart services and measured the impact of its use on the quality of automatic services among Umm Al-Qura University students. The research instruments used measured the quality of automatic services. The results of the research indicated that the application has a number of advantages, including encouraging students to actively participate in the learning process and contribute to effective communication between faculty members and students, in addition to providing multiple methods of communication between students. The results also indicated that there were no statistically significant differences at the level of 0.05 ; this indicates that the faculty type variable did not affect the level of satisfaction of Umm Al-Qura University students with the application, and that gender did not affect the level of satisfaction with the mobile application.
\end{abstract}

\section{Introduction}

Through the induction of previous studies and research, it becomes clear that there are many problems associated with communication with students at the Umm Al-Qura University. Some of these problems are related to communication with the university professor, student services being provided to the beneficiaries, some of which are related to communication with the Deanship of Admission and Registration and some related to communication with the Deanship of Student Affairs, as well as academic advising [1].

Since all university students in Saudi currently own smart phones, the information provided to them should be reliable. As the Saudi youth submit their ideas through the means of modern technology, they play the most prominent role in shaping public opinion and can easily fall prey to it. Without awareness or management, when they receive information and messages filled with destructive ideas on various topics, ranging from political, social, to even religious and believes in their validity. They subconsciously passes it on to other friends, only to form terrorist groups in this situation. Hence, our study aims at educating the university students of Saudi and make them aware of a unified source of information.

Umm Al-Qura University students suffer from a set of problems that can be summarized by the following points: lack of follow-up on university events and activities; the lack of a university communication channel to get to know the student information, rewards, study plan, academic schedule, transcripts, and inquiries about transactions; the lack of an application that provides student services in an interactive way with the university administration to interact with events and the ability to comment on and share them through social networks ; and linking the application to the Deanships of Admission and Registration, Student Affairs, the Deanship of Libraries, the schedule and results of courses, and the university calendar [2].

The current research provides a proposed solution to all previous problems faced by students at the Umm Al-Qura university, and it also contributes to the realization of Kingdom's vision (2030) by employing information technologies. The research develops a service product that links the university student with everything related to him at the 
university and facilitates him to complete many services through his smart mobile.

It should be noted that there are many current applications such as the Qassim university application at the Qassim University [3] and the official King Abdulaziz University application MYKAU [4] that enables all categories of users at the university to conduct their transactions and benefit from automatic services as the application contains public services available to visitors and all users and special services for certain groups, which appear according to the permissions after logging in. The Zarqa University application is the first of its kind in the field of providing various services to students, as the application contains more than 20 different services to serve students, where the student can inquire about his information through the application easily and quickly [5].

\section{Literature Review}

Recently and with the increase in the number of people using smart devices and keeping abreast of the great developments in the field of information and communication technology, many institutions these days are turning to the use of smart phone applications to quickly access services for companies and the parties they deal with. Designing and programming smart phone applications is one of the services that facilitate many tasks in our daily life [6].

The number of mobile phone subscriptions worldwide has reached nearly 6 billion, and nearly three-quarters of the world's population now owns mobile phones. Smartphone functions are increasing rapidly on the one hand, while the cost of these devices is decreasing on the other hand, which makes them affordable for everyone. Even in developing countries, global statistics indicate that the majority of smartphone users are young people, and university students rely heavily on technology: they do not read from a book but rather read from a screen and obtain information through various reference materials using the Internet, so it is necessary for teachers to meet these requirements and become capable of using the latest technology to develop innovative teaching methods to meet the learning needs [7].

In recent times, the trend in shifting from the use of traditional technologies such as the desktop computer to the use of mobile technologies such as the mobile phone is increasing. Almost all students nowadays own a mobile device, and nearly half of them own more than one. Therefore, nowadays students are well equipped for mobile learning. A recent research studied the impact of using smartphones and their applications to teach foreign languages, specifically English, highlighting its benefits and limitations for its use in teaching English as a foreign language [8].

This was done by conducting a literature search in the Web of Science, Scopus, and Science Direct databases and thus by evaluating the results of relevant studies. The results indicate that the use of smartphones and their applications generates positive effects on learning English as a foreign language, especially on the vocabulary of developing learners and their increased motivation for study. Another study illustrates a set of characteristics of mobile phone applications such as portability, their ability to provide information whenever the user needs to learn, and their design to fit personal learning in an adaptive way anytime and anywhere [9].

With the rapid increase in smartphone users around the world, mobile applications are increasing in number and popularity. The number of apps in the Google Play Store is about 2.1 million, while there are about 2.0 million and 669 thousand in the Apple App Store, Windows Store, and Amazon Appstore, and a study in 2017 showed that an average smartphone user in the United States of America uses more than 40 different applications per month. Smartphone users spend about two hours and 51 minutes on mobile applications per day, that is, more than a month and a half per year [10].

A recent work conducted an exploratory study prepared to measure the use of smart phones in enhancing access to Arabic digital content for the requirements and components of wireless publishing and concluded that the actual application of digital content technology based on the mobile phone in Arab information institutions is late, and that there is a weakness in the demand for digital content through a mobile phone [11].

Besides this, another research investigated the educational use of smart phone applications by university students, and the results indicated that most of the study sample students reported that they use smart phone applications for entertainment, and that the most used applications for obtaining information are search engines [12]. Moreover, another study pointed to the effectiveness of a training program based on the integrating cloud and mobile e-learning in education for developing the skills of using some smart phone applications [13].

In addition to this, a related work employed smart phone applications to raise awareness of family issues in the Sultanate of Oman and concluded that the use of smart phone applications contributes to the definition of services provided by institutions [14].

Furthermore, a recent communication aimed at understanding the circulation of information through smart phone applications by female students (BA) in the College of Computer and Information Sciences at Imam Muhammad bin Saud Islamic University and learning about the use of social networking applications in smart phones in the circulation of information by female students. The study involved female students graduating from the eighth level of the (bachelor's) level in the College of Computer and Information Sciences at Imam Muhammad bin Saud Islamic university, and the number of the study sample was 124 female students. In order to achieve the objectives of the study, the survey approach was used as the most appropriate research methodology, and the questionnaire was used as a tool to collect data related to the study, and it reached a set of results, including that all study samples (100\%) use social media applications on the smartphone to obtain information [15].

Another study scrutinized the use and effects of smart phones on faculty members at the university level, especially 
in the Kingdom of Saudi Arabia. The researchers conducted a survey using questionnaires. The questionnaires were distributed randomly to 66 members of the teaching faculty who owns a smartphone at Northern Border University. This study discovers that a smartphone has replaced a computer, and the email application was used mostly. Faculty members have also used smartphones as a means of sharing knowledge. Social media applications have been used extensively for teaching and learning [16].

Besides this, [17] presented a smartphone application using the App Inventor 2 platform: assessing student satisfaction through an analysis tool using the Likert scale. Mobile devices in high schools are increasingly present. The teacher instead of refusing to take advantage of this tool in order to provide a contribution to the discussion about the dilemma, a dedicated recruitment of the electrodynamics cycle was organized through an educational sequence. The research was developed in the second half of 2015. The sample consisted of 39 students from the third grade of high school, and our analysis depended on 3 closed questions from the data collection tool. Participants reported that using the app makes content more engaging, and they want to integrate this type of feature into other disciplines. They argued that using the apps contributed greatly in improving the understanding of the content. Thus, we understand that the smartphone should be used for activities aimed at teaching physics, but, like any other educational resources, it should not be the only one [17].

In addition to this, a recent study aimed at investigating analytically and quantitatively the potential in using smart phone applications and services in an educational environment, namely, the University of Bahrain, to visualize and educate university students about the library services that are available through their smartphones. Derived and for the purpose of data collection, two survey questionnaires were conducted and distributed; the first was designed to address student (university) users from two academic colleges at the University of Bahrain. This standard questionnaire is divided into two main parts: the first part covered the demographic elements, while the second part focused on their awareness of the various available smart phone services. Library use: the first part covered the perceived types of library services that are applicable through their smartphones and their willingness for services if offered, while the second is designed to address the library director and individual employees. Therefore, this paper aims to examine the availability and awareness of the University of Bahrain library services that are accessed through a smartphone. It is currently used by nearly every student who studies and uses the university library. The main findings indicated that respondents' perception about the adoption of smart phone applications for the library and the information services is very positive. The majority of respondents indicated their desire to become users of these services if offered. These key findings should assist information providers such as libraries and telecommunication service providers in designing a system that allows effective access to various information and library services using mobile phones. This study also reveals that there is still a need for more smart phone applications designed to support library users than ever before and that wireless application services remain unavailable, despite the increasing need of users [18].

Another work highlighted the employment of some mobile applications in remote training to develop the skills of using live broadcast sites in teaching staff members. The research relied on the descriptive, analytical, and experimental approach to achieve its goal. The research tools came in the form of a cognitive achievement test for some of the skills of using live broadcast sites and a test for the performance side of some skills of using live broadcast sites, and its tools were applied on a sample of 30 faculty members at the Islamic University who were chosen based on their desire to register their names to receive the proposed program remotely using a mobile app. The research concluded with a set of results, including that there is a statistically significant difference at the level of significance (0.01) between the mean of the preapplication scores and the average scores for the postapplication in the cognitive test for some of the skills of using live broadcast sites in teaching in favor of the postapplication. There is also a statistically significant difference at the level of significance (0.01) between the average scores of faculty members in the pre- and postapplications to test the performance of the use of live broadcast sites by some faculty members for the benefit of the postapplication. The research recommended the necessity to diversify the media that combines synchronous and asynchronous communication in training, in order to take into account the characteristics of the trainees and their work conditions [19].

A recent work by [20] studied the views of faculty members regarding the use of smartphones to enhance learning at the university level. In-depth interviews were conducted with 22 faculty members from various academic departments for this purpose. The responses of the interviewees were recorded, which were transcribed and analyzed. The results of this study indicate that the faculty members viewed smartphones as an effective way to learn off-campus and communicate with their peers and students. They also considered that smartphones were suitable for explaining complex topics to their students as the visual and audio content could easily be shared over the Internet. However, the majority of respondents were skeptical about using smartphones for educational purposes because they viewed them as a source of distraction and a waste of time. Moreover, they report the small size of both screen and keyboard as an important limiting factor undermining the efficient use of smartphones in education.

\section{Statement of the Problem}

When reviewing some of the smart applications provided by the Umm Al-Qura University, we find that they did not provide academic and research services to the university students, and this was evident by conducting interviews with 252 university students in various colleges, whose results confirmed the low services provided by these applications.

The results of the interviews also confirmed that university's smart applications lack some important services, including the lack of follow-up of university events and 
events; the lack of a university communication channel to get to know the student information, rewards, study plan, academic schedule, transcripts, inquiries about transactions; the lack of an application that provides student services in an interactive way with the university administration to interact with events and the ability to comment on and share them through social networks; and linking the application to the Deanships of Admission and Registration, Student Affairs, the Deanship of Libraries, the schedule and results of courses, and the university calendar. In light of the above, the research problem can be formulated in the following questions:

(1) What is the proposed electronic design for the application of smart services for university students?

(2) What are the advantages of a mobile application for smart services for university students?

(3) What are the disadvantages of the mobile application from the viewpoint of Umm Al-Qura University students?

(4) What is the level of satisfaction of students at Umm Al-Qura University from the online application?

(5) Does the level of satisfaction of Umm Al-Qura University students differ from the online application experience with the type of college and gender?

(6) What are the proposals for developing the mobile application for the students of the Umm Al-Qura University?

The research pursues to achieve the following objectives: determining the automatic services from the smart applications needed for students of the Umm Al-Qura University; developing a proposed vision for the application of smart services for university students; determining the degree of evaluation of a mobile application from the viewpoint of Umm Al-Qura University students; measuring the impact of the proposed electronic design for an application for smart services for university students on the quality of services provided to students of the Umm Al-Qura University. The research may contribute to improving the quality of automatic services provided to students of the Umm Al-Qura University.

\section{Research Methodology and Procedures}

The research used the descriptive and analytical approach to suit the nature of the research to describe and analyze the literature and previous studies in the field of design models of courses based on web pages, and the research also relied on the quasiexperimental approach for the purpose of designing a mobile application for smart services for the university student and measuring the impact of its use on the quality of services at Umm Al-Qura University students.

4.1. The Research Sample. The number of research participants from the Umm Al-Qura University was 234 students, which varied according to demographic variables. Table 1 shows a total statement of the participants according to the basic demographic variables.

Table 1 shows that 35.47 of the participants were from humanitarian and educational colleges, 9.82 from medical colleges, 25.64 from scientific and engineering colleges, 22.22 from Sharia colleges, and 6.83 from administrative colleges. It is also evident from the previous table that males represent $41.9 \%$ of the total number of the sample, while females represent $58.1 \%$ of the total number of the sample.

In order to achieve the objectives of the research, the quality of university services measure was built, which consisted of four themes. The first theme related to the advantages of the application included 7 phrases, and the second theme related to the negatives of the application included 7 phrases, and the third theme related to satisfaction with the application included 7 phrases, and the fourth theme related to the development proposals included 7 phrases.

The reliability of the scale was calculated using the alpha Cronbach coefficient, and Table 2 shows the coefficients of the stability of the different themes of the scale and its overall stability.

It is clear from Table 2 that Cronbach's alpha coefficients for the stability of the scale with its different themes ranged between 0.747 and 0.897 , all of which are high reliability coefficients with which the researchers are confident to obtain stable results.

The validity of the internal consistency factor of the scale was calculated by calculating the correlation coefficient between the numerical estimates of the response of the sample on the items of each theme and the total degree of the theme, and Table 3 shows the correlation coefficients.

It is evident from Table 3 that all the correlation coefficients between the scale items and the degree of the theme belonging to it were positive, high, and a function at the level of 0.01 , which indicates a high internal consistency of the scale.

\section{Mobile App Design}

The instructional design was based on the general model (ADDIE) as illustrated in Figure 1.

Description of each stage of the design is given in the following sections.

\subsection{Analysis.}

(1.1) Analyzing the prior needs and experiences related to the necessary services for the university student

(1.2) Analyzing the contents of each service according to the degree of importance

(1.3) Identifying the objectives of the instructional services and the entry requirements

(1.4) Analyzing the characteristics of the target sample (UQU students)

5.2. Design. Stages of application design involve the following: 
TABLE 1: Description of the study sample according to the basic demographic variables.

\begin{tabular}{|c|c|c|c|c|c|c|c|}
\hline \multicolumn{8}{|l|}{ Variable } \\
\hline \multirow{3}{*}{ Participating colleges } & & $\begin{array}{l}\text { Humanitarian and } \\
\text { educational colleges }\end{array}$ & Medical colleges & $\begin{array}{c}\text { Scientific and } \\
\text { engineering colleges }\end{array}$ & $\begin{array}{l}\text { Sharia } \\
\text { colleges }\end{array}$ & $\begin{array}{l}\text { Administrative } \\
\text { colleges }\end{array}$ & Total \\
\hline & Nr. & 83 & 23 & 60 & 52 & 16 & 234 \\
\hline & $\%$ & 35.47009 & 9.82906 & 25.64103 & 22.22222 & 6.837607 & 100 \\
\hline \multirow{3}{*}{ Gender } & & Male & Female & Total & & & \\
\hline & Nr. & 98 & 136 & 234 & & & \\
\hline & $\%$ & $41.9 \%$ & $58.1 \%$ & $100.0 \%$ & & & \\
\hline
\end{tabular}

TABLE 2: The stability coefficients of the various themes of the scale and its overall stability.

\begin{tabular}{lccccc}
\hline Theme & Average & Variance & Standard deviation & Nr. of phrases & Alpha coefficient \\
\hline Application positives & 24.9359 & 30.344 & 5.50849 & 7 & 0.897 \\
Application negatives & 21.6325 & 26.740 & 5.17106 & 7 & 7 \\
Satisfaction with the application & 27.4444 & 19.604 & 4.42766 & 7 & 0.869 \\
Development proposals & 29.9915 & 9.682 & 3.11164 & 0.747 & 0.752 \\
\hline
\end{tabular}

TABLE 3: Correlation coefficients between the scale items and the overall degree of the theme to which they belong.

\begin{tabular}{lccccccccc}
\hline Ready & & \multicolumn{2}{c}{ Positives } & \multicolumn{2}{c}{ Negatives } & \multicolumn{2}{c}{ Satisfaction } & \multicolumn{2}{c}{ Development proposals } \\
$\begin{array}{l}\text { Sentence } \\
\text { number }\end{array}$ & $\begin{array}{c}\text { Correlation } \\
\text { coefficient }\end{array}$ & $\begin{array}{c}\text { Sentence } \\
\text { number }\end{array}$ & $\begin{array}{c}\text { Correlation } \\
\text { coefficient }\end{array}$ & $\begin{array}{c}\text { Sentence } \\
\text { number }\end{array}$ & $\begin{array}{c}\text { Correlation } \\
\text { coefficient }\end{array}$ & $\begin{array}{c}\text { Sentence } \\
\text { number }\end{array}$ & $\begin{array}{c}\text { Correlation } \\
\text { coefficient }\end{array}$ & $\begin{array}{c}\text { Sentence } \\
\text { number }\end{array}$ & $\begin{array}{c}\text { Correlation } \\
\text { coefficient }\end{array}$ \\
\hline 1 & $0.787^{* *}$ & 1 & $0.834^{* *}$ & 1 & $0.710^{* *}$ & 1 & $0.669^{* *}$ & 1 \\
2 & $0.627^{* *}$ & 2 & $0.858^{* *}$ & 2 & $0.461^{* *}$ & 2 & $0.755^{* *}$ & 2 & $0.495^{* *}$ \\
3 & $0.747^{* *}$ & 3 & $0.775^{* *}$ & 3 & $0.714^{* *}$ & 3 & $0.811^{* *}$ & 3 & $0.774^{* *}$ \\
4 & $0.766^{* *}$ & 4 & $0.734^{* *}$ & 4 & $0.678^{* *}$ & 4 & $0.606^{* *}$ & 4 & $0.777^{* *}$ \\
5 & $0.818^{* *}$ & 5 & $0.686^{* *}$ & 5 & $0.693^{* *}$ & 5 & $0.679^{* *}$ & 5 & $0.758^{* *}$ \\
6 & $0.812^{* *}$ & 6 & $0.817^{* *}$ & 6 & $0.710^{* *}$ & 6 & $0.757^{* *}$ & 6 & $0.638^{* *}$ \\
& & 7 & $0.775^{* *}$ & 7 & $0.701^{* *}$ & 7 & $0.755^{* *}$ & 7 & $0.781^{* *}$ \\
\hline
\end{tabular}

${ }^{* *}$ Function at level $0.01 ;{ }^{*}$ function at level 0.05 .

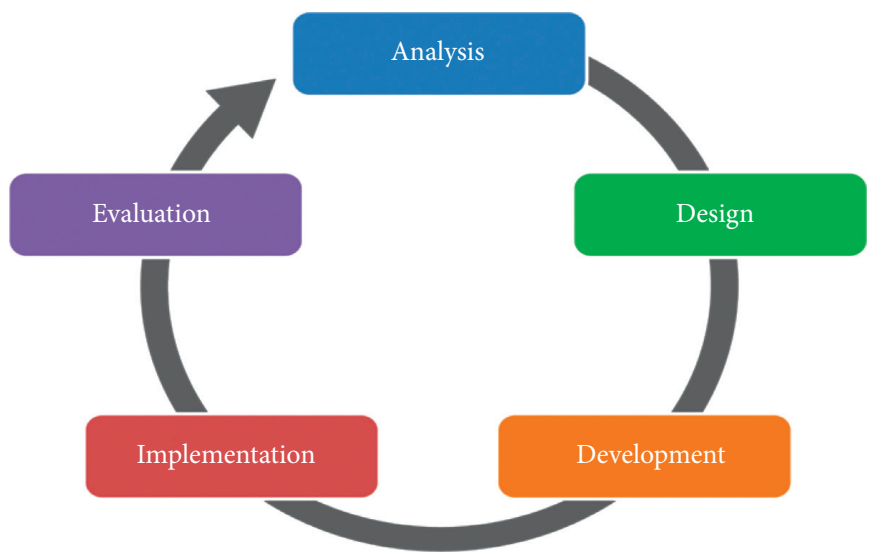

Figure 1: The instructional model (ADDIE) [21].

(2.4.1) Instituting and introducing the application

(2.4.2) Organizing and distributing the contents of the electronic application in a graphical interface

(2.4.3) Refining the application self-assessment tools

(2.4.4) Writing the performance objectives

(2.4.5) Preparing the script

\subsection{Development.}

(1.1) Programming the electronic application for smart phones

(1.2) Identifying the event panel, backgrounds, and the forward, backward, and undo buttons

(1.3) Selecting the colors and highlighting the presentations 


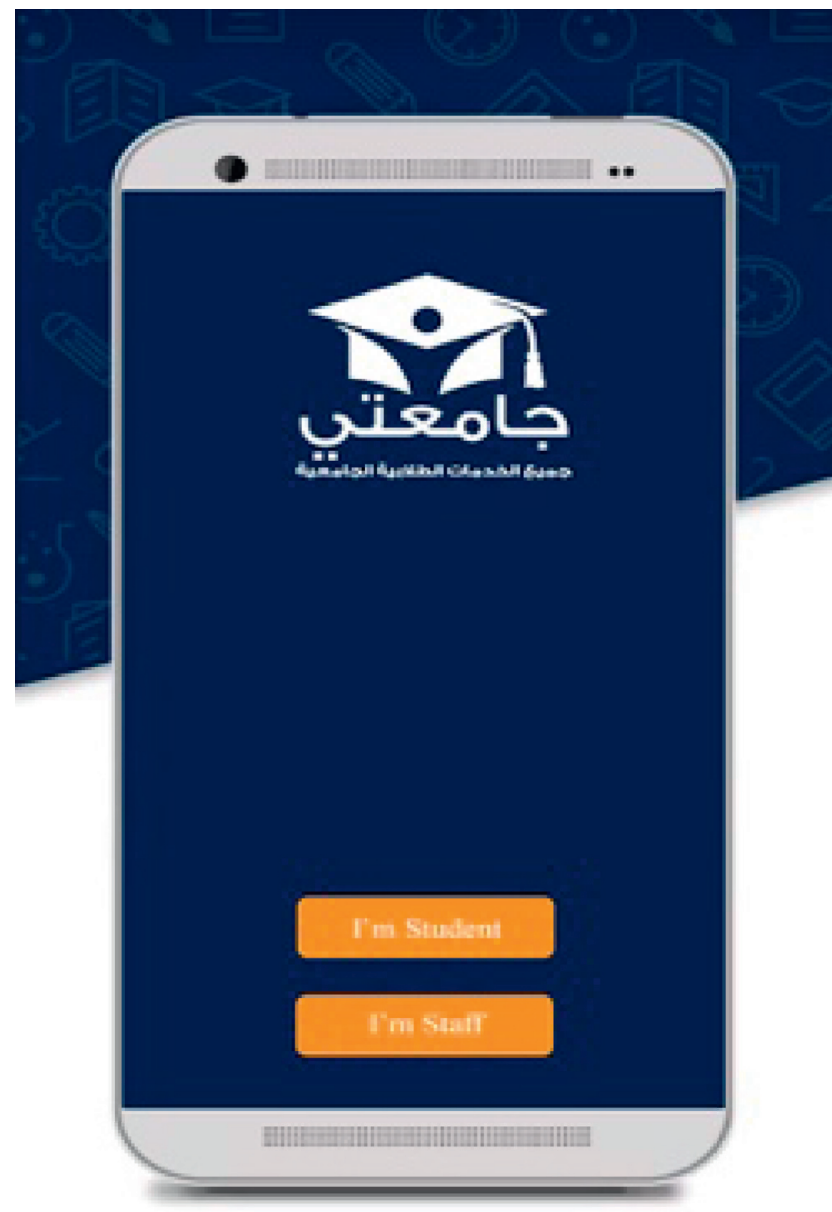

Figure 2: The first screen of the designed AI-enabled mobile app.

5.4. Implementation. This stage includes making the application available for students through the Google Play Store to be easily accessed through all Android system devices used by the students. Furthermore, the program navigation icons and buttons become obvious.

5.5. Evaluation. To ensure accuracy and overcome the problems of the design, all the contents of the application are passed through a formative assessment and subjected to scientific and technical judgement by academic jury members. Moreover, a user guide was prepared for students to help them feasibly use the application.

\section{Mobile App Evaluation}

The formative evaluation was used for all the application vocabulary by presenting the content to the arbitrators to judge the scientific and technical aspect in the preparation for determining the accuracy of the work and overcoming the problems in the design by modifying any notes. A guide has been prepared for students on using the application. Figures 2-5 demonstrate screens of the mobile app.

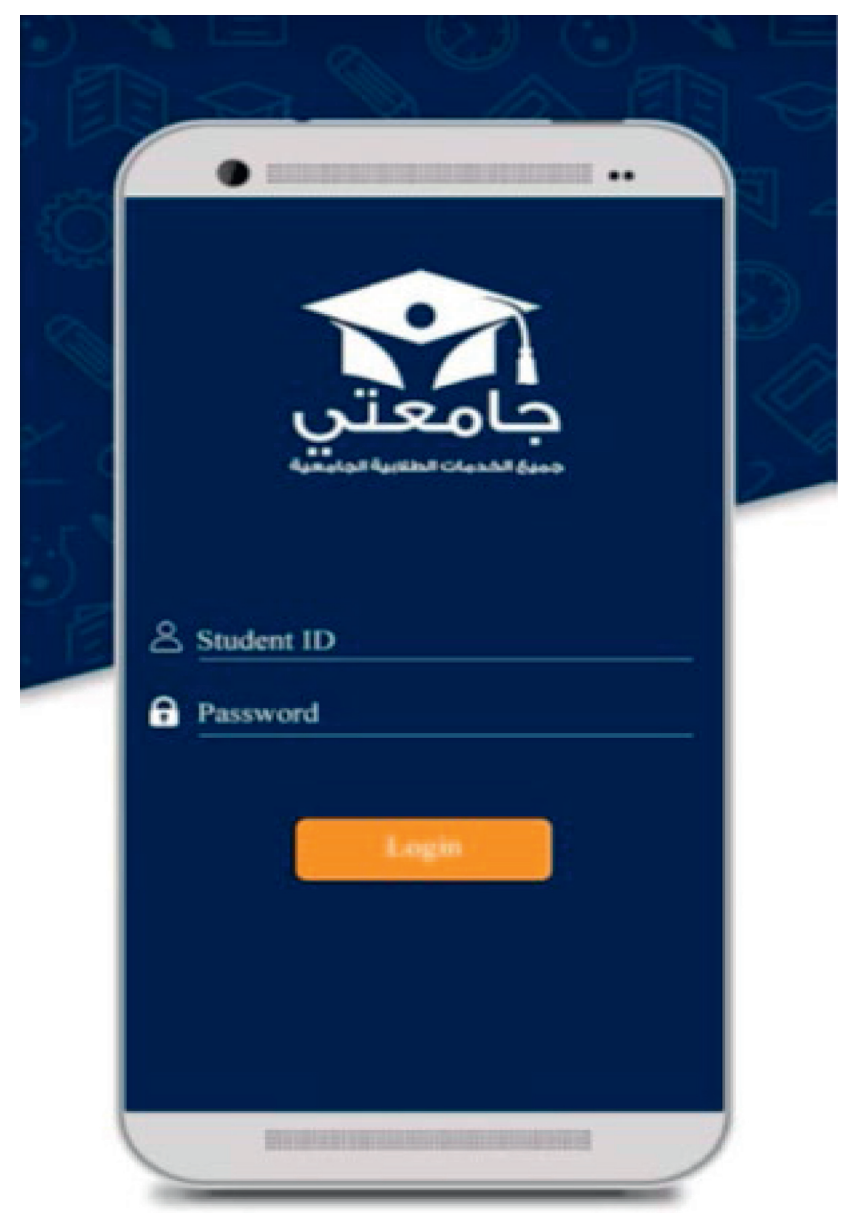

Figure 3: Login screen AI-enabled mobile app.

\section{Results and Discussion}

7.1. Monitoring the Advantages of the Proposed AI-Enabled Mobile App. The results of this theme are related to the second question of the research questions, the text of which is "What are the advantages of a mobile application for smart services for the university student?" To answer this question, the frequencies, percentages, and Chi-square values were calculated to obtain the differences between their response, as well as the weighted average, and its percentage of the total score on the vocabulary of the theme related to the advantages of the mobile application, Table 4 shows the results.

It is evident from Table 4 that the students of the Umm Al-Qura University who participated in the response from the scale agreed on the advantages and positives that all the theme statements included, except for statement No. (6), as their response indicated a neutral position on it where all the values of Chi-square were a function at the level of 0.05 , and the significance came in favor of the response (agree) in all the statements except for statement No. (6), the text of which is "the mobile application increased the motivation of the students." The indication came in favor of the response (neutral), and their weighted response averages also indicated that the sample members agree with these statements, except for statement No. (6), whose mean indicates the 


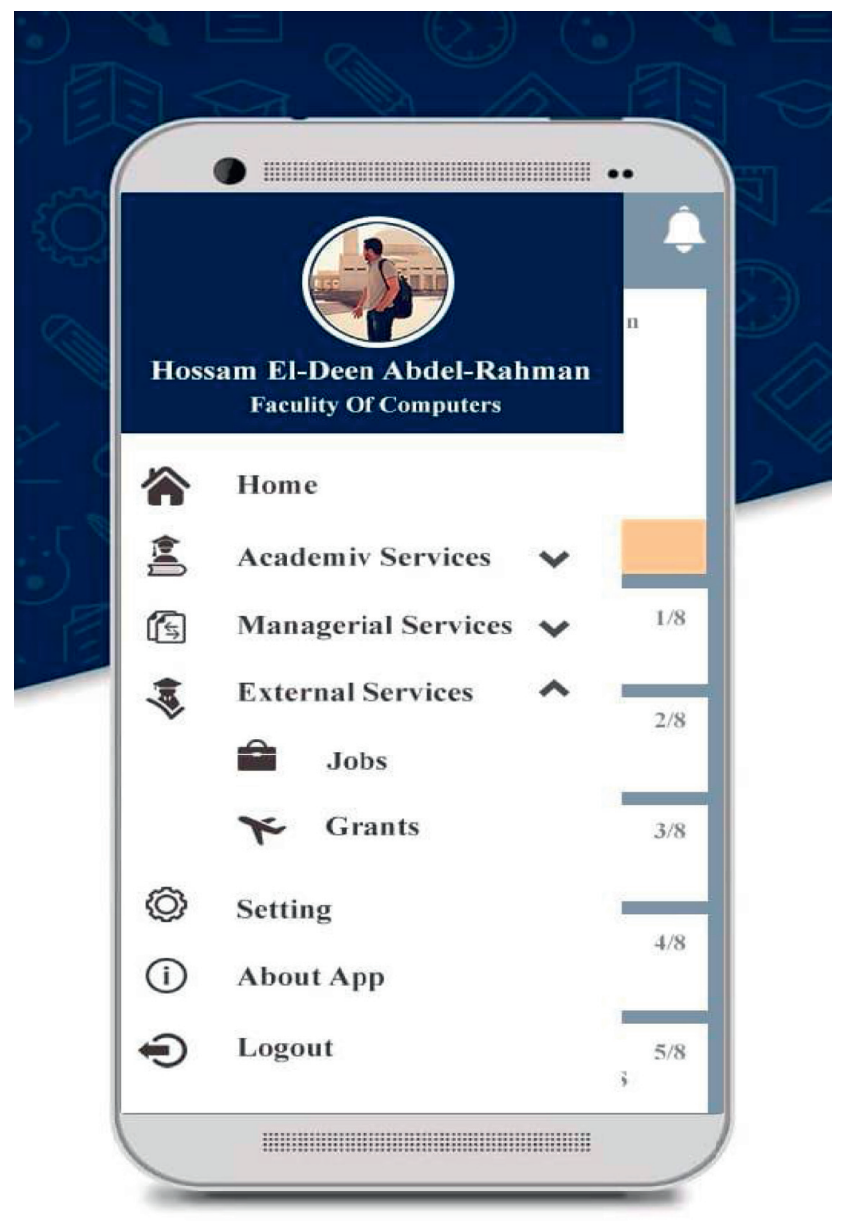

FIgURE 4: Student services AI-enabled mobile app.

response (neutral). Accordingly, the proposed mobile application at the Umm Al-Qura University has a number of features included in the previous table.

7.2. Monitoring the Disadvantages of the Proposed AI-Enabled Mobile App. The results of this theme are related to the third question of the research questions, the text of which is "What are the negatives of the mobile application from the viewpoint of the students of Umm Al-Qura University?"

To answer this question, the frequencies, percentages, and Chi-square values were used to calculate the differences between their response, as well as the weighted average, and the percentage of the total score on the vocabulary of the theme on the negatives of the mobile application. Table 5 illustrates these results.

The results included in Table 5 indicate the following.

Umm Al-Qura University students agreed that there are two disadvantages in the mobile application.

Some students were busy while using the mobile application about achieving educational goals. The value of the Chi-square for the differences between the occurrences of the sample responses to this statement was a function, and the significance was directed in favor of the agreed response with the highest frequency, and its weighted average was

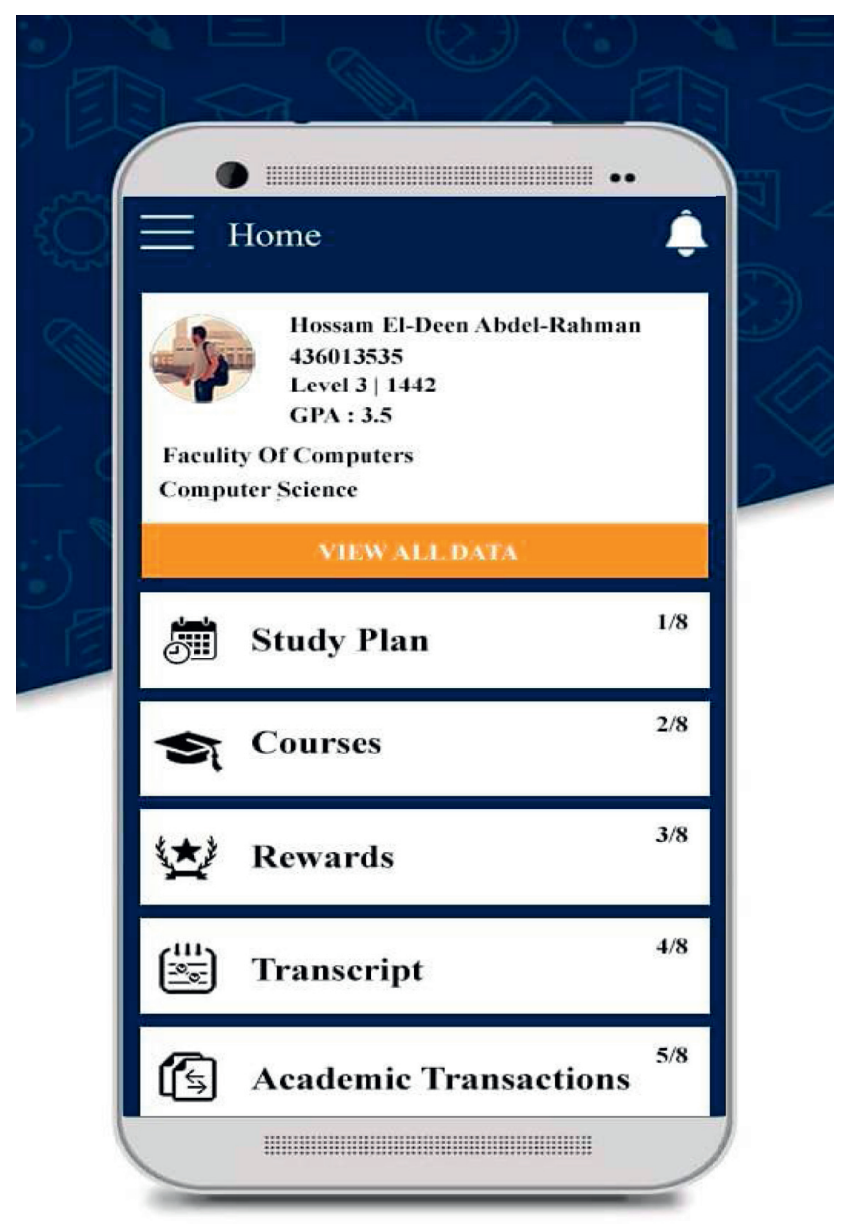

FIgURE 5: Student academic services AI-enabled mobile app.

71.79 , which indicates the sample's approval of this statement.

The mobile application was not compatible with achieving its objective. The value of the Chi-square to calculate the differences between the frequency of the respondents' responses to this statement was also significant, and the significance was directed in favor of the response with the highest frequency.

Umm Al-Qura University students did not agree "I felt frustrated while using the mobile application due to the lack of technical efficiency" as the value of the Chi-square to calculate the differences between the frequencies of the sample responses to this item was indicative, and the indication was in favor of the higher frequency and the response was (without agreement), as indicated by the percentage of their weighted average on this phrase to count approval.

The results also indicate the neutrality of Umm Al-Qura University students towards the rest of the four statements, and if the Chi-square values indicate the presence of differences between the frequencies of their response in favor of disagree, the ratio of their average response to the overall score of the statement indicates that the sample may be neutral towards these negatives or that their opinions do not tend to be clearly accepted or rejected. This also shows the 
TABLE 4: The frequencies and percentages of the sample responses regarding the advantage of the mobile application.

\begin{tabular}{|c|c|c|c|c|c|c|c|c|c|}
\hline Phrases & & $\begin{array}{l}\text { Strongly } \\
\text { disagree }\end{array}$ & $\begin{array}{l}\text { Without } \\
\text { agreement }\end{array}$ & Neutral & Agree & $\begin{array}{l}\text { Strongly } \\
\text { agree }\end{array}$ & $\begin{array}{l}\text { Chi- } \\
\text { square }\end{array}$ & Average & $\begin{array}{c}\text { Approval } \\
\text { percentage and } \\
\text { degree }\end{array}$ \\
\hline \multirow{2}{*}{$\begin{array}{l}\text { The application encouraged students } \\
\text { to actively participate in the learning } \\
\text { process }\end{array}$} & $\mathrm{F}$ & 10 & 40 & 50 & 85 & 49 & \multirow[b]{2}{*}{61.4} & \multirow[b]{2}{*}{3.52} & \multirow{2}{*}{$\begin{array}{l}70.51 \\
\text { Agree }\end{array}$} \\
\hline & $\%$ & 4.3 & 17.1 & 21.4 & 36.3 & 20.9 & & & \\
\hline \multirow{2}{*}{$\begin{array}{l}\text { The application contributed to the } \\
\text { development of various aspects of } \\
\text { students' learning }\end{array}$} & $\mathrm{F}$ & 8 & 44 & 58 & 90 & 34 & \multirow[b]{2}{*}{78.3} & \multirow[b]{2}{*}{3.41} & \multirow{2}{*}{$\begin{array}{l}68.38 \\
\text { Agree }\end{array}$} \\
\hline & $\%$ & 3.4 & 18.8 & 24.8 & 38.5 & 14.5 & & & \\
\hline \multirow{2}{*}{$\begin{array}{l}\text { The application enabled effective } \\
\text { communication between me and the } \\
\text { students }\end{array}$} & $\mathrm{F}$ & 5 & 34 & 49 & 106 & 40 & \multirow[b]{2}{*}{116.8} & \multirow[b]{2}{*}{3.6} & \multirow{2}{*}{$\begin{array}{l}72.14 \\
\text { Agree }\end{array}$} \\
\hline & $\%$ & 2.1 & 14.5 & 20.9 & 45.3 & 17.1 & & & \\
\hline \multirow{2}{*}{$\begin{array}{l}\text { The application provided multiple } \\
\text { ways to communicate between } \\
\text { students }\end{array}$} & $\mathrm{F}$ & 4 & 29 & 46 & 113 & 42 & \multirow[b]{2}{*}{140.1} & \multirow[b]{2}{*}{3.7} & \multirow{2}{*}{$\begin{array}{l}73.68 \\
\text { Agree }\end{array}$} \\
\hline & $\%$ & 1.7 & 12.4 & 19.7 & 48.3 & 17.9 & & & \\
\hline \multirow{2}{*}{$\begin{array}{l}\text { The application added a kind of } \\
\text { freedom in dealing with information }\end{array}$} & $\mathrm{F}$ & 1 & 19 & 36 & 135 & 43 & \multirow{2}{*}{230.3} & \multirow{2}{*}{3.85} & 77.09 \\
\hline & $\%$ & 0.4 & 8.1 & 15.4 & 57.7 & 18.4 & & & Agree \\
\hline \multirow{2}{*}{$\begin{array}{l}\text { The application increased students' } \\
\text { motivation }\end{array}$} & $\mathrm{F}$ & 13 & 52 & 80 & 64 & 25 & \multirow{2}{*}{65.2} & \multirow{2}{*}{3.15} & 63.08 \\
\hline & $\%$ & 5.6 & 22.2 & 34.2 & 27.4 & 10.7 & & & Neutral \\
\hline \multirow{2}{*}{$\begin{array}{l}\text { The app provided instant feedback to } \\
\text { the learner }\end{array}$} & 2 & 5 & 23 & 55 & 107 & 44 & \multirow[t]{2}{*}{128.4} & \multirow[t]{2}{*}{3.69} & 73.85 \\
\hline & & 2.1 & 9.8 & 23.5 & 45.7 & 18.8 & & & Agree \\
\hline \multicolumn{8}{|c|}{ Theme as a whole } & 3.56 & 71.25 \\
\hline
\end{tabular}

TABLE 5: The frequencies and percentages of the sample responses regarding the advantage of the mobile application.

\begin{tabular}{|c|c|c|c|c|c|c|c|c|c|c|}
\hline Nr. & Phrases & & $\begin{array}{l}\text { Strongly } \\
\text { disagree }\end{array}$ & $\begin{array}{l}\text { Without } \\
\text { agreement }\end{array}$ & Neutral & Agree & $\begin{array}{l}\text { Strongly } \\
\text { agree }\end{array}$ & $\begin{array}{l}\text { Chi- } \\
\text { square }\end{array}$ & Average & $\begin{array}{l}\text { Percentage of } \\
\text { approval and its } \\
\text { rating }\end{array}$ \\
\hline \multirow[b]{2}{*}{1} & \multirow{2}{*}{$\begin{array}{l}\text { I was bored while using the app } \\
\text { due to the lack of human } \\
\text { interaction }\end{array}$} & $\mathrm{F}$ & 9 & 86 & 43 & 63 & 33 & \multirow[b]{2}{*}{73.35} & \multirow[b]{2}{*}{3.10} & \multirow{2}{*}{$\begin{array}{c}62.14 \\
\text { Neutral }\end{array}$} \\
\hline & & $\%$ & 3.8 & 36.8 & 18.4 & 26.9 & 14.1 & & & \\
\hline \multirow[b]{2}{*}{2} & \multirow{2}{*}{$\begin{array}{l}\text { I was frustrated while using the } \\
\text { app due to my lack of technical } \\
\text { competence }\end{array}$} & $\mathrm{F}$ & 57 & 138 & 25 & 13 & 1 & \multirow[b]{2}{*}{259.33} & \multirow[b]{2}{*}{1.98} & \multirow{2}{*}{$\begin{array}{c}39.74 \\
\text { Without Agree }\end{array}$} \\
\hline & & $\%$ & 24.4 & 59 & 10.7 & 5.6 & 0.4 & & & \\
\hline \multirow[b]{2}{*}{3} & \multirow{2}{*}{$\begin{array}{l}\text { Sudden technical hardware and } \\
\text { network failures were repeated } \\
\text { while using the application }\end{array}$} & $\mathrm{F}$ & 18 & 73 & 32 & 83 & 28 & \multirow{2}{*}{72.62} & \multirow[b]{2}{*}{3.12} & \multirow{2}{*}{$\begin{array}{c}62.56 \\
\text { Neutral }\end{array}$} \\
\hline & & $\%$ & 7.7 & 31.2 & 13.7 & 35.5 & 12 & & & \\
\hline \multirow{2}{*}{4} & \multirow{2}{*}{$\begin{array}{l}\text { Building the app took a lot of } \\
\text { time and effort }\end{array}$} & $\mathrm{F}$ & 16 & 75 & 44 & 73 & 26 & \multirow{2}{*}{61.34} & \multirow{2}{*}{3.07} & 61.54 \\
\hline & & $\%$ & 6.8 & 32.1 & 18.8 & 31.2 & 11.1 & & & Neutral \\
\hline \multirow[b]{2}{*}{5} & \multirow{2}{*}{$\begin{array}{l}\text { Some students were busy while } \\
\text { using the app about achieving } \\
\text { educational goals }\end{array}$} & $\mathrm{F}$ & 7 & 34 & 59 & 82 & 52 & \multirow[b]{2}{*}{67.58} & \multirow[b]{2}{*}{3.58} & \multirow{2}{*}{$\begin{array}{l}71.79 \\
\text { Agree }\end{array}$} \\
\hline & & $\%$ & 3 & 14.5 & 25.2 & 35 & 22.2 & & & \\
\hline \multirow{2}{*}{6} & Health problems appeared, such & $\mathrm{F}$ & 13 & 71 & 47 & 69 & 34 & \multirow{2}{*}{50.96} & \multirow{2}{*}{3.17} & 63.42 \\
\hline & as eyestrain or back pain & $\%$ & 5.6 & 30.3 & 20.1 & 29.5 & 14.5 & & & Neutral \\
\hline \multirow{3}{*}{7} & \multirow{2}{*}{\multicolumn{2}{|c|}{ The app was not fit for purpose }} & 8 & 31 & 67 & 75 & 53 & \multirow{2}{*}{64.03} & \multirow{2}{*}{3.57} & 71.45 \\
\hline & & & 3.4 & 13.2 & 28.6 & 32.1 & 22.6 & & & Agree \\
\hline & \multicolumn{8}{|c|}{ Theme as a whole } & 3.09 & $\begin{array}{c}61.81 \\
\text { Neutral }\end{array}$ \\
\hline
\end{tabular}

weighted percentage of the total score of the expressions in their total response to the questionnaire, as it reached 61.81, which indicates the response to be neutral.

7.3. Monitoring the Students' Level of Satisfaction. The results of this theme are related to the fourth question of the research questions, which reads, "What is the level of satisfaction of Umm Al-Qura University students about the mobile application?"

To answer this question, the frequencies, percentages, and Chi-square values were calculated to calculate the differences between their response, as well as the weighted average, and its percentage for the total score on the 
TABLE 6: The frequencies and percentages of the sample responses regarding the advantage of the mobile application.

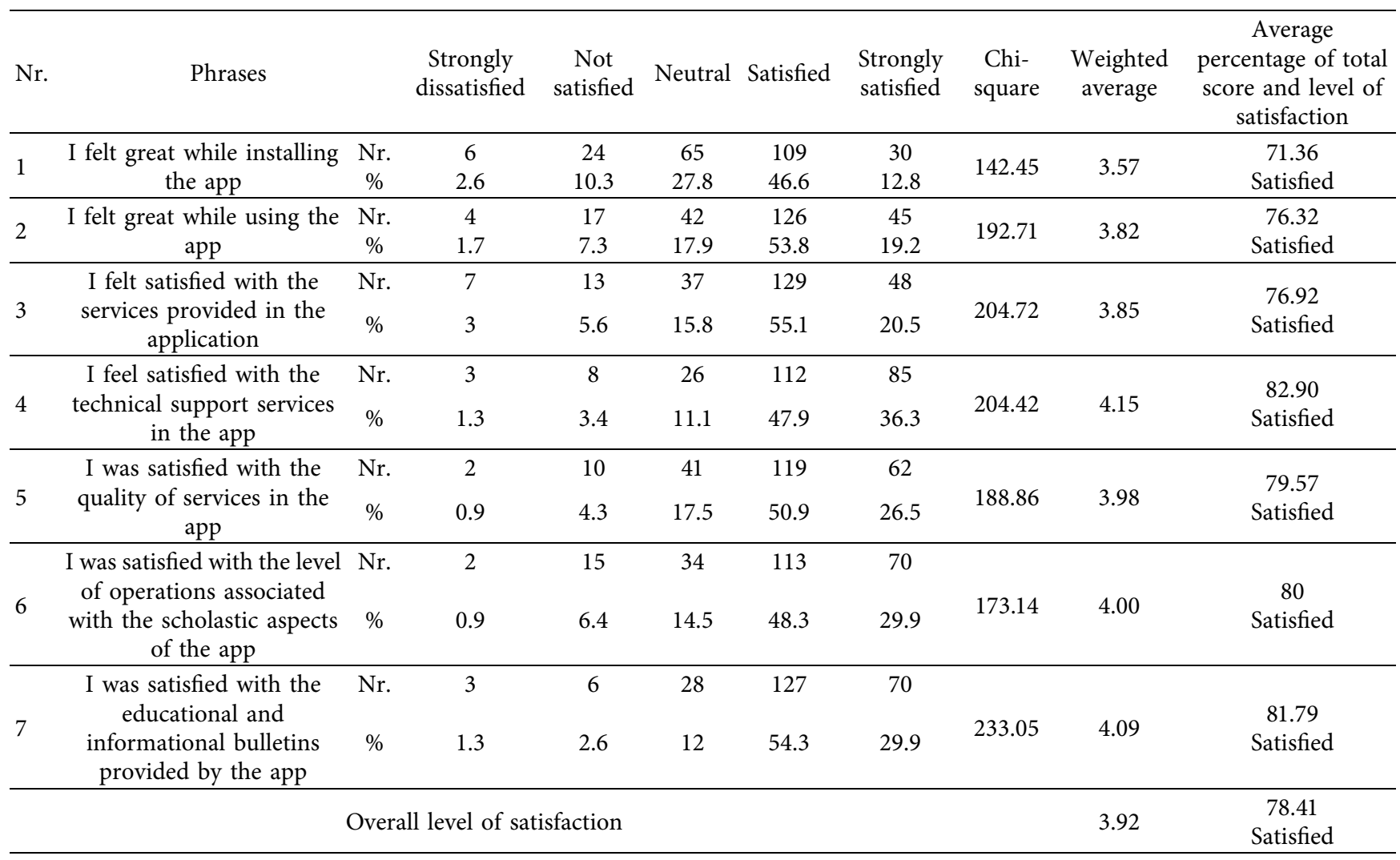

vocabulary of the theme of Umm Al-Qura University students' satisfaction with the mobile application. Table 6 illustrates these results.

It is evident from Table 6 that the students of the Umm Al-Qura University participating in response to the questionnaire are satisfied with the online application. While all the values of the Chi-square were used to calculate the differences between the occurrences of their response, all of them function at the level of 0.05 , and the significance was directed in all expressions in favor of the repetition satisfied with the highest frequencies, and all the percentages of the weighted average to the total score of the expressions indicated the level of the response satisfied. The general average of these responses is a percentage of the total score of 78.41 , which also indicates that the level of response is satisfied.

7.4. Students' Level of Satisfaction Differences Based on College and Gender. The results of this theme are related to the fifth question of the study questions, which reads: "Does the level of satisfaction of Umm Al-Qura University students differ from the mobile application experience with the type of college and gender?" These results will be presented according to each of the previous variables.

Results related to the impact of the type of college students belong to on their level of satisfaction with the online application at the Umm Al-Qura University: to ascertain the effect of the variable of the type of college to which the UQU students belong, a one-way analysis of variance (ONE WAY ANOVA) was used between the total of their digital grades on the theme of satisfaction with application. Table 7 illustrates these results.

It is evident from Table 7 that the value of $q$ to calculate the difference between the numerical averages of the responses of Umm Al-Qura University students in their categories according to the type of college to which they belong (humanitarian and educational colleges-medical colleges-scientific and engineering colleges-Sharia collegesadministrative colleges) amounted to 2,653, which is a nonvalue. Statistically significant difference at 0.05 level indicates that this variable does not affect Umm Al-Qura University students' satisfaction with the mobile application.

7.5. Gender Effects on Online App Satisfaction. To ascertain the effect of Umm Al-Qura University students' gender (male/female) on their level of satisfaction with the mobile application, the $T$-test was used for two independent groups to calculate the difference between the averages of the digital estimates of their responses to the theme of satisfaction with the mobile application. Table 8 illustrates this.

It is evident from Table 8 that the value of $t$ to calculate the difference between the numerical estimates of the response of male and female students at the Umm Al-Qura University to the theme of satisfaction with the mobile application was 1.48 , which is a nonstatistically significant value at the level of 0.05 , which indicates that gender does not affect their level of satisfaction with the mobile application. 
TABLE 7: The results of one-way analysis of variance to calculate the differences between the responses of the sample on the satisfaction about the mobile application according to the type of college.

\begin{tabular}{lccccc}
\hline Contrast sources & Sum of squares & Degree of freedom & Average squares & $F$ & Significance/indication \\
\hline Between groups & 154.253 & 4 & 38.563 & & \\
Within groups & 3328.807 & 229 & 14.536 & 2.653 & Not significant at the 0.05 level \\
Total & 3483.060 & 233 & & \\
\hline
\end{tabular}

TABLE 8: T-test results to calculate satisfaction about the mobile application according to the gender variable.

\begin{tabular}{lcccccc}
\hline Gender & Nr. & Average & Standard deviation & The calculated $T$ value & Degree of freedom & Significance/indication \\
\hline Male & 98 & 22.8571 & 4.36953 & \multirow{2}{*}{1.48} & 232 & Not significant at the 0.05 level \\
Female & 136 & 23.6176 & 3.44063 & & & \\
\hline
\end{tabular}

TABLE 9: The frequencies and percentages of their responses to the suggested improvements of the mobile application.

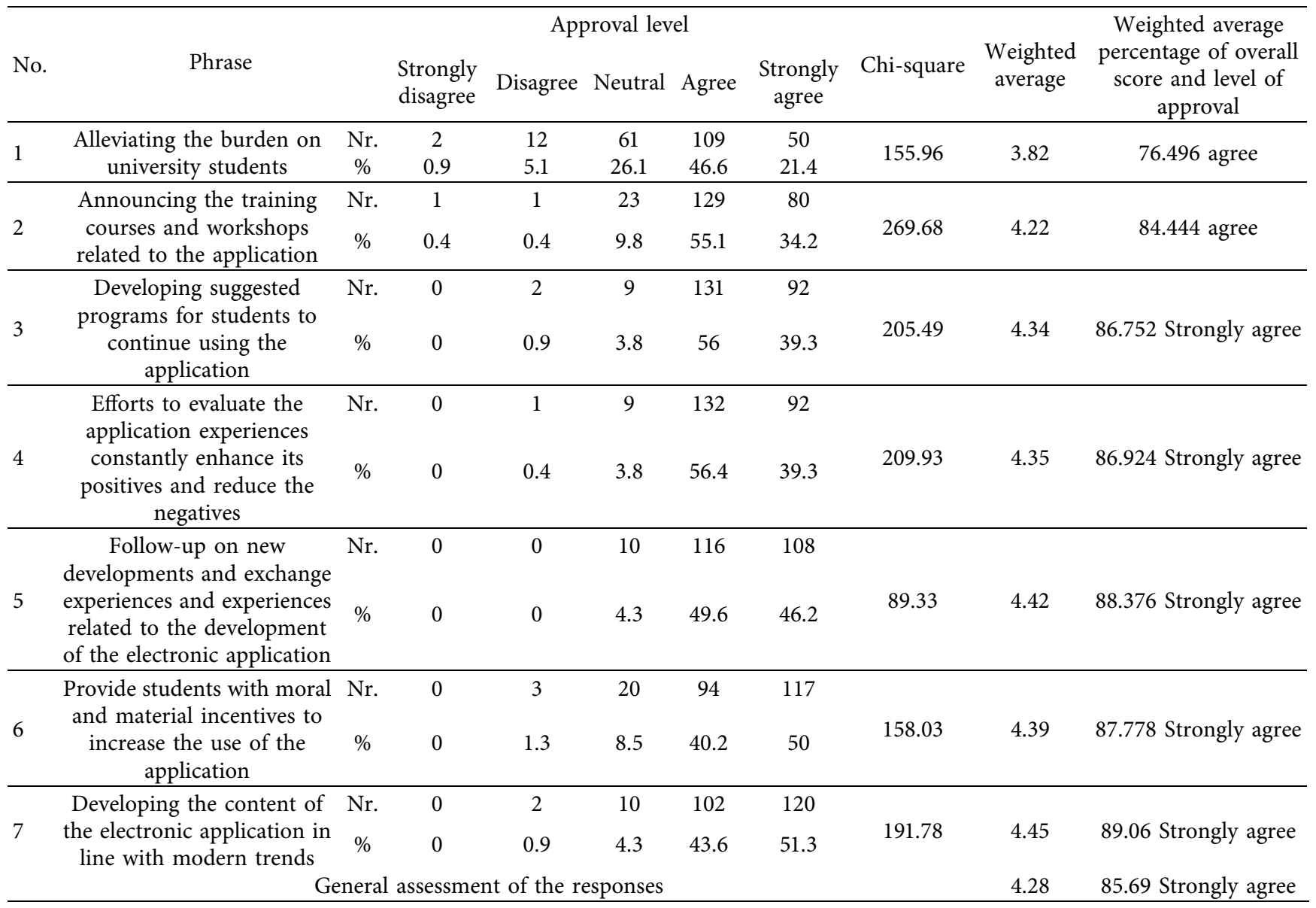

7.6. Students' Proposals about the App. The results of this theme are related to the sixth question of the study questions, which reads: "What are the proposals for developing the mobile application from the viewpoint of the students of the Umm Al-Qura University?"

In order to answer this question, the frequencies and percentages of the responses of Umm Al-Qura University students to this theme were calculated. Chi-square was used to calculate the difference between the frequency of their response to this theme, the weighted average and its percentage, and the level of their approval of each suggested improvement which completed this theme. Table 9 shows these results.

It is evident from Table 9 that the Umm Al-Qura University students agree to the development proposals included in the previous theme as the values of the Chisquare for the difference between the occurrences of their response were all indicative at the level of 0.05 , and the 
significance in the first five statements is directed to the response in agreement, while in terms 6 and 7 of the response, it is strongly agreed. The highest frequency and weighted average ratios of the overall score indicate that the level of their approval of the proposals falls below the level of the response agree in the first three proposals, while it falls below the level of response strongly agree in the rest of the statements, and the ratio of the general weighted average of the theme to the overall score of the response indicates the approval of the university Umm Al-Qura on the development proposals, in general, at a level that we strongly agree.

\section{Conclusion and Future Work}

The number of smart phone users has increased significantly around the world. It is stated that there are more than 2 million mobile apps in the Google Play store. These apps are designed for a variety of purposes, for example, business, tourism, and educational. Enabling such apps with advanced technology such as AI can enhance their benefits for users. The research aimed at designing an AI-enabled mobile app for educational purposes. To be more specific, it was designed for Umm Al-Qura University students. The goal is to measure app's service quality among the university students. The results indicated that the app has both advantages and disadvantages, and yet, overall, the majority of students were satisfied. Future work will involve introduction of more advanced technology such as Internet of things (IoT) to the mobile app.

\section{Data Availability}

The data used to support the findings of this study are available from the corresponding author upon request.

\section{Conflicts of Interest}

The authors declare that there are no conflicts of interest regarding the publication of this article.

\section{Acknowledgments}

The authors thank the Deanship of Scientific Research at the Umm Al-Qura University for supporting this work under Grant Code 18-COM-1-01-0005.

\section{References}

[1] A. M. Almalki, "Blended learning in higher education in saudi arabia: a study of Umm al-Qura University," Doctoral dissertation, RMIT University, Melbourne, Victoria, Australia, 2011.

[2] M. Elnagar, "Information science department, Umm Al-qura university: a study of its quantitative and methodological trends, and the problems facing them," International Journal of Library and Information Science, vol. 4, no. 1, pp. 78-113, 2017.

[3] A. Store, "Qassim university-student services," 2021, https:// apps.apple.com/sa/app/id604830962\#?platform=iphone.

[4] KAU, MY KAU, KAU, Karlstad, Sweden, 2021, https://mykau. kau.edu.sa/Default-223111-EN.
[5] G. Play, “AlZarqa my University," 2021, https://play.google. com/store/apps/details?id=com.zudevelopingteam. app\&hl=ar\&gl=US.

[6] R. R. Ahmed, F. Salman, S. A. Malik, D. Streimikiene, R. H. Soomro, and M. H. Pahi, "Smartphone use and academic performance of university students: a mediation and moderation analysis," Sustainability, vol. 12, no. 1, p. 439, 2020.

[7] C. Giachetti and G. Marchi, "Successive changes in leadership in the worldwide mobile phone industry: the role of windows of opportunity and firms' competitive action," Research Policy, vol. 46, no. 2, pp. 352-364, 2017.

[8] B. Klímová, "Mobile phones and/or smartphones and their apps for teaching English as a foreign language," Education and Information Technologies, vol. 23, no. 3, pp. 1091-1099, 2018, p.

[9] Y. Mehdipour and H. Zerehkafi, "Mobile learning for education: benefits and challenges," International Journal of Computational Engineering Research, vol. 3, no. 6, pp. 93-101, 2013.

[10] U. Mahbub, J. Komulainen, D. Ferreira, and R. Chellappa, "Continuous authentication of smartphones based on application usage," IEEE Transactions on Biometrics, Behavior, and Identity Science, vol. 1, no. 3, pp. 165-180, 2019, p.

[11] A. Al-Sayed, "The use of mobile phones to enhance access to digital arabic content, a study of wireless publishing requirements and its constituents, i know," 2012.

[12] C. Reese Bomhold, "Educational use of smart phone technology," Electronic Library And Information System, vol. 47, no. 4, pp. 424-436, 2013.

[13] M. Desouki and M. A. Al-Nur, For the Effectiveness of a Training Program Based on the Integration of Cloud and Mobile E-Learning in Developing the Skills of Using Some Smart Phone Applications in Education for the Basic Education Teacher, Cairo, the Fourteenth Scientific Conference Entitled: Technology of Distance Education and E-Training and Aspirations for Modernization In the Arab World-the Egyptian Society for Educational Technology, the Egyptian Society for Educational Technology and the Faculty of Education, pp. 135-175, Al-Azhar University, Cairo, Egypt, 2014.

[14] W. B. S. B. K. Al-Alaweya, "Employing smartphone applications in awareness of family issues in the sultanate of Oman, Egypt," Journal of Studies in Social Service and Human Sciences, vol. 39, no. 16, pp. 268-296, 2015.

[15] M. B. D. A. Al-Khathami, "Smartphone applications by female students of the college of computer and information Sciences at Imam Muhammad bin Saud islamic university: descriptive study, Jordan," The Jordanian Journal of Social Sciences, vol. 9, no. 1, pp. 75-92, 2016.

[16] H. M. Alfawareh and S. Jusoh, "The use and effects of smartphones in higher education," International Journal of Interactive Mobile Technologies (iJIM), vol. 11, no. 6, pp. 103-111, 2017.

[17] U. J. Raminelli, M. P. de Souza Filho, and C. M. de P Raminelli, "Application for smartphones using the app inventor 2 platform: evaluating the degree of student satisfaction through an instrument of analysis using the Likert scale," InFor, vol. 3, pp. 69-85, 2017.

[18] A. H. Abdulrazzaq and M. Al-Ani, "The awareness and use of smartphone applications to the available services of the university of Bahrain library: a proposed application," Journal of WEI Business and Economics, vol. 7, no. 1, pp. 22-32, 2018.

[19] Abdel Wahab and M. M. Mohamed, "Employing some mobile applications in remote training to develop the skills of using 
live broadcast sites in teaching staff members," Education Journal, vol. 59, pp. 641-667, 2019.

[20] S. Iqbal and Z. A. Bhatti, "A qualitative exploration of teachers' perspective on smartphones usage in higher education in developing countries," International Journal of Educational Technology in Higher Education, vol. 17, no. 1, pp. 1-16, 2020.

[21] R. M. Branch, Instructional Design: The ADDIE Approach, Springer, New York, NY, USA, 2009. 